\title{
Effect of latex reclaim on physico-mechanical and thermal properties of carbon black filled natural rubber/butadiene rubber composite
}

\author{
Vaishak Nambiathodi $^{1} \mathbb{C} \cdot$ Siby Varghese $^{1} \cdot$ Neethu Varghese $^{1}$
}

Received: 28 May 2021 / Accepted: 9 September 2021 / Published online: 20 September 2021

(c) The Malaysian Rubber Board 2021

\begin{abstract}
As a material having high rubber content, latex reclaim (white reclaim) has been used in the production of premium grade rubber products like tyres, retreading materials, etc. Introduction of latex reclaim (LR) is also an ideal method to reduce the cost of rubber products. In the present work, natural rubber (NR), butadiene rubber (BR), and latex reclaim (LR) combinations were prepared to develop cost efficient tread materials. LR was mixed with NR/BR at various proportions to produce tread materials which will comply with national specifications. The blends were prepared and the cure and mechanical properties were investigated. Results have indicated that the scorch time and cure time had decreased with the increase of reclaim loading. The mechanical properties like tensile strength, tear strength, abrasion resistance decrease with the increase in the LR content. It was found that $70-80 \%$ of the mechanical properties were retained even after addition of $30 \mathrm{phr}$ of LR. The thermal behaviour and activation energy of NR/BR/LR system was investigated using thermogravimetry TGA analysis and increased activation energy showed that the thermal stability has increased when the amount of LR is high. SEM studies had indicated the morphology change due to the viscosity mismatch between NR and BR especially in the presence of LR.
\end{abstract}

Keywords Activation energy $\cdot$ Blend ratio $\cdot$ Coat-Redfern plots $\cdot$ Latex reclaim $\cdot$ NR $\cdot$ BR blend $\cdot$ Thermogravimetric analysis $\cdot$ SEM analysis

\section{Introduction}

Natural rubber (NR) latex has been widely used in many applications ranging from everyday items to specialised ones. Excellent stretch and recovery are the unique properties that make NR desirable for several applications. In medical sector, they are used in suction catheters, medical gloves, stethoscope tubing, elastic bandages, reservoir breathing bags, blood pressure cuffs, etc. In domestic applications they are used in the production of balloons, carpet backing, raincoats, cosmetic sponges, etc. The finished products from natural rubber latex exhibit excellent elongation, tear resistance and recovery. The demand for latex products especially gloves is huge now-a-days. Due to Covid-19 pandemic situation, there is a large demand for medical gloves and prophylactic devices. This information

Vaishak Nambiathodi

vaishakn10@gmail.com

1 Technical Consultancy Division, Rubber Research Institute of India, Rubber Board P.O., Kottayam 686009, Kerala, India is provided by Fortune Business Insights ${ }^{\mathrm{TM}}$, in its report, titled, "Disposable Medical Gloves Market, 2020-2027." The world demand for examination gloves before Covid-19 was 1.3 billion pieces and the current demand is 2.7 billion pieces. Accordingly, the production sites have huge number of off-grade gloves and wastes $[1,2]$. The reclamation of rubber from rubber products is a commercial practice and the resulting reclaimed rubber can impart increased processability and reduced cost to the products [3, 4].

According to market research, the global reclaimed rubber market size is estimated to reach $\$ 6.53$ billion by 2026 growing at a CAGR of $12.03 \%$ during the forecast period. Rising price of natural rubber have forced almost all sectors to use low-cost reclaimed rubber. Construction sectors are consuming reclaimed rubber in flat roof covering on account of weather and heat ageing properties. The increased demand of electronics, packaging and other industrial applications have positively influenced the demand of reclaimed rubber. Among the available types of reclaimed rubbers, the latex reclaimed rubber has gained much attention among manufactures $[5,6]$. As a material having good rubber content and lower filler, latex reclaim (white reclaim) has got wide 
Table 1 ASRTU specification for precured tread rubber

\begin{tabular}{ll}
\hline Nature of test & Specified value \\
\hline Hardness IRHD, Shore A & $60-70$ \\
$300 \%$ modulus $\left(\mathrm{Kg} / \mathrm{cm}^{2}\right)$ & 100, Min \\
Tensile strength $\left(\mathrm{Kg} / \mathrm{cm}^{2}\right)$ & 200, Min \\
Elongation at break $(\%)$ & $400 \mathrm{Min}$ \\
Abrasion Resistance Index & $160 \mathrm{Min}$ \\
\hline
\end{tabular}

attention in the production of premium grade rubber products like tyres, retreading materials, etc. A large percentage of latex waste products is accumulated among manufactures due to defects like pinholes, crates, blisters, etc. Rubber Research Institute of India have developed a suitable method to reclaim latex waste and have obtained optimum mechanical properties [7]. Since LR has high hydrocarbon content, it has the potential to be reused to develop rubber products with superior qualities [8-10]. Devulcanisation of medical gloves waste in the presence of MBTS as reclaiming agent was prepared using mechano-chemical process [11]. Cure rate was found to be improved by blending the reclaim with natural rubber.

In the present work LR has been incorporated with NR/ BR blends in various proportions. A series of NR/BR blends were prepared with an aim to produce retreading material complying with national specifications (Table 1). Three series say 60/40 (series A), 50/50 (series B), and 40/60 (series C) NR/BR blends were selected for the study. The rheological, mechanical and thermal behaviour was examined with a view to produce low-cost retreading material without sacrificing the properties.

\section{Experimental}

\section{Materials}

The BR used in this study was a linear polymer (Sabic 4610) manufactured by solution polymerisation process using stereo specific nickel catalyst and NR (ISNR 5) was obtained from Rubber Research Institute of India, Kottayam. The technical details of the rubbers used are given in Tables 2. NR-based latex reclaim (commercial grade) was used in the study. Laboratory grade zinc oxide was obtained from Emerk Ltd., Mumbai. The coarse white powder has a specific gravity of 5.47. Antioxidants, antidegradants, accelerators and pre-vulcanisation inhibitor (PVI) were provided by NOCIL Ltd, Mumbai. Staining type Antioxidant Pilnox TDQ was in the form of light brown pastille with a specific gravity of 1.1. Antidegradant Pilflex 13 is an alkyl-aryl-PPD with a specific gravity of $0.986-1.00$ at $60{ }^{\circ} \mathrm{C}$. Delayed action sulphenamide
Table 2 Technical details of rubbers

\begin{tabular}{|c|c|c|}
\hline Rubber type & Parameters & Limit \\
\hline \multirow[t]{7}{*}{ ISNR 5} & Dirt content, $\%$ by mass, $\max$ & 0.05 \\
\hline & Volatile matter, $\%$ by mass, $\max$ & 0.80 \\
\hline & Nitrogen, $\%$ by mass, max & 0.60 \\
\hline & Ash, $\%$ by mass, $\max$ & 0.60 \\
\hline & Initial plasticity, $\mathrm{P}_{\mathrm{o}}$, Min & 30 \\
\hline & Plasticity retention index, PRI, min & 60 \\
\hline & Mooney viscosity & 85 \\
\hline \multirow[t]{5}{*}{ Sabic 4610} & $\begin{array}{l}\text { Mooney viscosity, (ML } 1+4 \text {, } \\
100^{\circ} \mathrm{C} \text { ) }\end{array}$ & 46 \\
\hline & Volatile matter, $\%$ by mass, $\max$ & 0.50 \\
\hline & Organic acid (\%) & $0.775 \pm^{-} 0.375$ \\
\hline & Ash, $\%$ by mass, $\max$ & 0.25 \\
\hline & cis 1,4 content $(\%)$, min & 96.0 \\
\hline \multirow{8}{*}{$\begin{array}{l}\text { Latex reclaim } \\
\text { (NR-based } \\
\text { LR) }\end{array}$} & Rubber hydrocarbon content, $\%$ & 79 \\
\hline & Filler content (Inorganic), $\%$ & 12.9 \\
\hline & Acetone extract & 7.9 \\
\hline & Residual accelerators, $\%$ & 48 \\
\hline & Moisture content, $\%$ & 1 \\
\hline & Specific gravity & 1.09 \\
\hline & Gel content, \% & 75 \\
\hline & $\begin{array}{l}\text { Mooney viscosity, (ML 1+4, } \\
100^{\circ} \mathrm{C} \text { ) }\end{array}$ & 30 \\
\hline
\end{tabular}

accelerator Pilcure MOR was used as accelerator in this study. The off white to light tan crystalline powdered PVI has a specific gravity of 1.33 at $25^{\circ} \mathrm{C}$. PG chemicals, Kerala supplied paraffin wax with a melting point of $58-60{ }^{\circ} \mathrm{C}$ and density of 0.82 . N-grade wood rosin and stearic acid (Melting point: $70{ }^{\circ} \mathrm{C}$ ) was supplied by Sameera Chemical Pvt. Ltd. Orient black 330 was supplied by Phillips Carbon Black Limited. High aromatic heavy bodied rubber process oil (Aromatic oil) was supplied by Indian Oil Corporation.

\section{Preparation of NR/BR/LR vulcanisate}

All the rubber compounds were prepared in two stagesinitially a masterbatch consisting of NR, BR, LR and other additives except the curing systems were mixed in a laboratory model Intermix (Francis Shaw, KO Intermix MK3) of capacity of $1 \mathrm{~L}$. The final mixes were prepared according to the formulation given in Table 3 in a laboratory size two-roll mixing mill $(150 \times 325 \mathrm{~mm})$ at a friction ratio of 1:1.25 according to ASTM 3182-07. The temperature of the roll was maintained at $60^{\circ} \mathrm{C}$ by circulating cold water. The curing of the compounds were carried out in a hydraulic press at temperature of $150{ }^{\circ} \mathrm{C}$. 
Table 3 Formulation for blend compounds

\begin{tabular}{|c|c|c|c|c|c|c|c|c|c|c|c|c|}
\hline \multirow[t]{2}{*}{ NR/BR } & \multicolumn{4}{|c|}{$60 / 40(\mathrm{phr})$} & \multicolumn{4}{|c|}{$50 / 50(\mathrm{phr})$} & \multicolumn{4}{|c|}{ 40/60 (phr) } \\
\hline & A0 & A1 & A2 & A3 & B0 & B1 & B2 & B3 & $\mathrm{C} 0$ & $\mathrm{C} 1$ & $\mathrm{C} 2$ & $\mathrm{C} 3$ \\
\hline NR & 60 & 50 & 40 & 30 & 50 & 40 & 30 & 20 & 40 & 30 & 20 & 10 \\
\hline BR & 40 & 40 & 40 & 40 & 50 & 50 & 50 & 50 & 60 & 60 & 60 & 60 \\
\hline LR & 0 & 10 & 20 & 30 & 0 & 10 & 20 & 30 & 0 & 10 & 20 & 30 \\
\hline $\mathrm{ZnO}$ & 4 & & & & 4 & & & & 4 & & & \\
\hline Stearic acid & 2 & & & & 2 & & & & 2 & & & \\
\hline N330 & 50 & & & & 50 & & & & 50 & & & \\
\hline Aromatic oil & 8 & & & & 8 & & & & 8 & & & \\
\hline TDQ & 1 & & & & 1 & & & & 1 & & & \\
\hline 6-PPD & 1 & & & & 1 & & & & 1 & & & \\
\hline Paraffin wax & 1 & & & & 1 & & & & 1 & & & \\
\hline Wood rosin & 2 & & & & 2 & & & & 2 & & & \\
\hline Sulphur & 2.25 & & & & 2.25 & & & & 2.25 & & & \\
\hline MOR & 1 & & & & 1 & & & & 1 & & & \\
\hline Retarder & 0.20 & & & & 0.20 & & & & 0.20 & & & \\
\hline
\end{tabular}

\section{Characterisation}

\section{Processing characteristics}

The cure time $\left(t_{90}\right)$ was measured using a Monsanto Rheometer (Rheometer MDR 2000) at a temperature of $150{ }^{\circ} \mathrm{C}$ and scorch time $\left(t_{5}\right)$ was measured using a Mooney viscometer (MV 2000 Alpha Technologies, USA) at a temperature of $138^{\circ} \mathrm{C}$.

\section{Thermal analysis}

The thermogravimetric analysis (TGA) of NR/BR/LR blends were analysed using a thermogravimetric analyser in nitrogen atmosphere (flow rate $40 \mathrm{~mL} / \mathrm{min}$ ) in the temperature range $30-800{ }^{\circ} \mathrm{C}$. The heating rate was $20^{\circ} \mathrm{C} / \mathrm{min}$ up to $600{ }^{\circ} \mathrm{C}$ and then changed to $30{ }^{\circ} \mathrm{C} / \mathrm{min}$ till $800{ }^{\circ} \mathrm{C}$. The activation energy for decomposition was calculated using Coat Redfern equation [12]:

$\log \left[-\log \frac{1-\alpha}{T^{2}}\right]=\log \left[\frac{A R}{\beta E}\left(1-\frac{2 R T}{E}\right)\right]-\frac{E}{2.303 R T}$

where $\alpha$ is the fractional mass loss at time $t, T$ is the absolute temperature, $A$ is the pre-exponential factor, $R$ is the universal gas constant, $\beta$ is the heating rate and $E$ is the activation energy. A plot between $\log \left[-\log (1-\alpha) / T^{2}\right]$ and $1 / T$ gives a straight line with slope- $E / 2.303 R$ and $y$-intercept $\log [A R / \beta E$ $(1-2 R T / E)]$.

\section{Mechanical properties}

The mechanical properties of the blends were tested according to ASTM standards. Tensile (ASTM D 412) and tear properties (ASTM D 624) were measured with a universal testing machine (Zwick/Roell model Z 005(Germany) at a cross head speed of $500 \mathrm{~mm} / \mathrm{min}$. Type $\mathrm{C}$, an un-nicked test piece with a $90^{\circ}$ angle on one side and with tab ends was used to measure the tear strength. Abrasion resistance (ASTM D 5963-04) was measured using a rotary drum abrader and is expressed as volume loss in cubic millimeters or abrasion resistance as index. Heat build-up (ASTM D 623-07) was measured using Goodrich flexometer at a temperature of $50{ }^{\circ} \mathrm{C}$. Hardness was measured at five different positions of the samples using a Shore A Hardness Tester (ASTM D 2240). Crosslink density measurements were calculated using Flory and Rehner equation as follows:

$V_{r}=\frac{D / \rho_{p}}{D / \rho_{p}+A_{o} / \rho_{s}}$

$M_{c}=\frac{-\rho_{p} V_{s} V_{r}^{1 / 3}}{\ln \left(1-V_{r}\right)+V_{r}+0.42\left(V_{r}\right)^{2}}$

$v=\frac{1}{2 M_{c}}$ 
where $D$ and $\rho_{\mathrm{p}}$ are the weight and density of dry rubber (for vulcanised rubber, $\rho_{\mathrm{p}}=0.9203 \mathrm{gcm}^{3}$ and $A_{\mathrm{o}}$ and $\rho_{\mathrm{s}}$ are the weight and density of solvent (for toluene, $\rho_{\mathrm{s}}=0.865 \mathrm{gcm}^{3}$, $v=$ crosslink density, $M_{\mathrm{c}}$ is the molecular weight between the cross-links, $V_{\mathrm{s}}$ is the molar volume of the solvent.

\section{Carbon black dispergrader}

The macro level dispersion of each surface was analysed using the dispergrader according to ISO 11345 . The test piece having approximate cross-section of $8 \mathrm{~mm}$ thickness and $10 \mathrm{~mm}$ width was freshly cut from the sample using a single edge razor blade cutter.

\section{Scanning electron microscope}

The phase morphology of the cured NR/BR/LR system was analysed using SEM analysis (JEOL, JSM 6490LA) at a tilt angle of $0^{0}$ after the coating the specimen surface with gold. The tensile fractured surface of 50/50 NR/BR blend with varying reclaim rubber content $(0,10,20,30 \mathrm{phr})$ was selected for the SEM studies.

\section{Results and discussion}

\section{Cure characteristics}

From Fig. 1, it can be seen that the cure time is maximum with the blend system without latex reclaim and it decreases as the proportion of LR increased. This may be due to the migration of residual curatives from the LR [13-15]. As expected, the scorch safety decreased with the increase in the LR content. The lower value of scorch time and increased crosslink density on addition of reclaimed rubber (Table 4) may be due to the presence of residual curatives in the reclaimed rubber [16-18].

\section{Tensile strength}

It can be seen that (Fig. 2) there is a continuous reduction in tensile strength in all the series upon addition of reclaimed rubber. The maximum reduction was observed with $30 \mathrm{phr}$ LR. Upon ageing of the samples, the tensile showed continuous decrease which is sharper with $30 \mathrm{phr}$ addition of LR. In series A, the reduction of tensile strength was gradual whereas in series B and C sudden decrease was noticed on addition of above $20 \mathrm{phr}$ of LR. However, it is observed that in all the three systems $75-80 \%$ retention in properties was observed even after the addition of $30 \mathrm{phr}$ of LR. The percentage reduction after ageing was less in virgin blends compared to LR added mixes. The percentage reduction of tensile strength
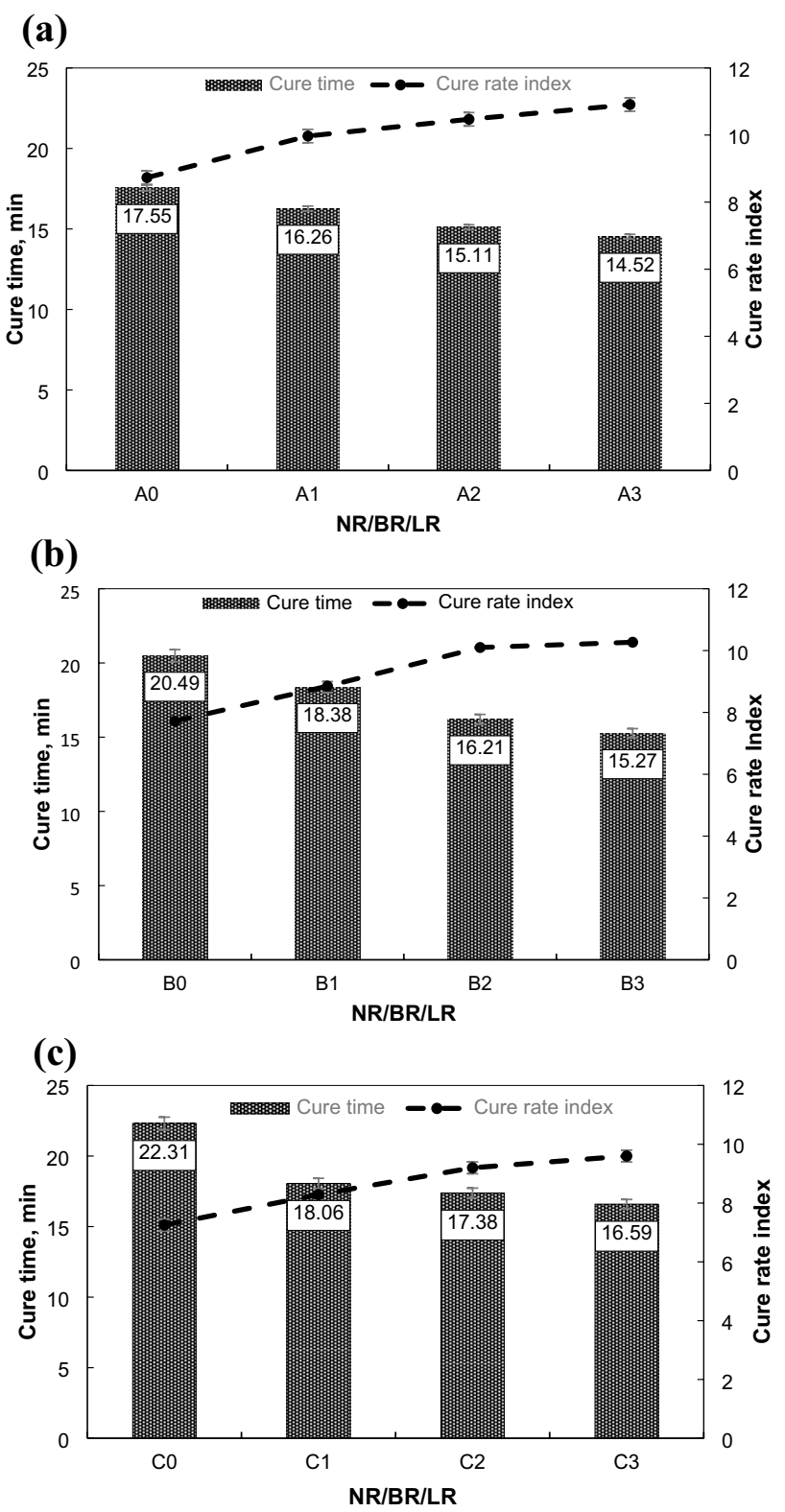

Fig. 1 Plots of cure time and cure rate index of A 60/40 NR:BR, B 50/50 NR:BR and C 40/60 NR:BR with various combination LR

in series $\mathrm{A} 0, \mathrm{~B} 0$ and $\mathrm{C} 0$ was $2.4,3$ and $6.5 \%$, respectively and the rate of reduction found to increase with the addition of LR. [19]

\section{Elongation at break}

From the Fig. 3, it can be seen that there is a progressive reduction in the elongation at break upon addition of LR. This might be due to the incorporation of low molecular weight latex reclaim in the blend. It is also reported that the increased crosslink density may impart a reduction in 
Table 4 Cure characteristics of NR/BR blends incorporated with LR

\begin{tabular}{llll}
\hline System & Compounds & $\begin{array}{l}\text { Scorch time, } \\
\left(t_{5}\right) \text { min }\end{array}$ & $\begin{array}{l}\text { Cross link den- } \\
\text { sity } \times 10^{-5}, \mathrm{~mol} / \\
\mathrm{cm}^{3}\end{array}$ \\
\hline $60 / 40$ & A0 & 21.12 & 5.6725 \\
& A1 & 15.81 & 6.6101 \\
& A2 & 13.28 & 6.8925 \\
& A3 & 13.13 & 7.4564 \\
$50 / 50$ & B0 & 21.45 & 5.5220 \\
& B1 & 17.88 & 6.4381 \\
& B2 & 14.02 & 7.9254 \\
& B3 & 13.10 & 8.0124 \\
$40 / 60$ & C0 & 23.02 & 5.9235 \\
& C1 & 15.33 & 7.9536 \\
& C2 & 14.80 & 8.2341 \\
& C3 & 13.22 & 8.3201 \\
\hline
\end{tabular}

elongation with LR. Higher the crosslink density, lower will be the chain mobility. The reduced chain mobility and flexibility resulted in lower elongation at break [20, 21].

(a)

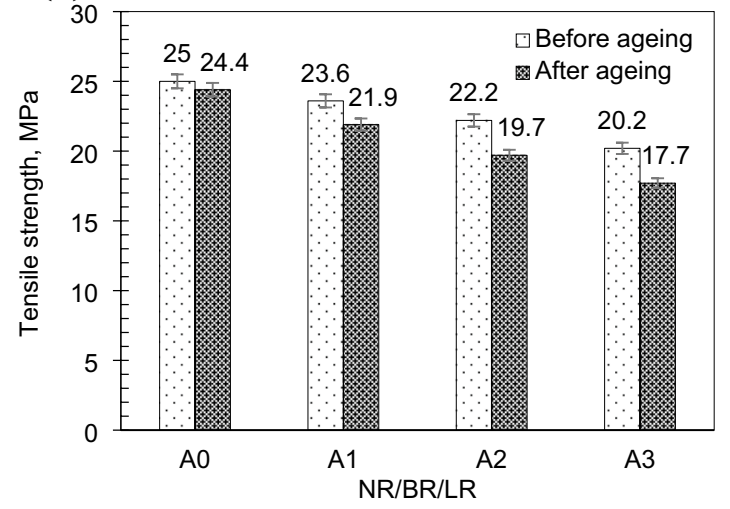

\section{Modulus at 100 and modulus $300 \%$ elongation}

It can be seen that there is an increase in the moduli at 100 and $300 \%$ elongation (Fig. 4). This may be attributed to the increased crosslinking in the blends due to the presence of residual crosslinking agent in the blends. But, the values of modulus did not change significantly with crosslink density. This is because, the presence of gel is predominant factor in determining the modulus compared to crosslink density and crosslink density distribution in NR/BR/LR blends [22]. It was reported that the reinforcement index M300/M100 can be used as a criterion for analysing the rolling resistance of tire. Higher the value, lower will be the rolling resistance [23]. From the Fig. 5, it is observed that in NR rich blends there is continuous reduction in M300/M100 reinforcement index whereas in SR rich blends up to $10 \mathrm{phr}$ addition of LR the value increased and thereafter it decreased.

\section{Tear strength}

From the Fig. 6, it can be seen that in NR rich systems, the tear strength increased by $14 \%$ which maintains with up to $30 \mathrm{phr}$ addition of LR. LR has comparatively good rubber

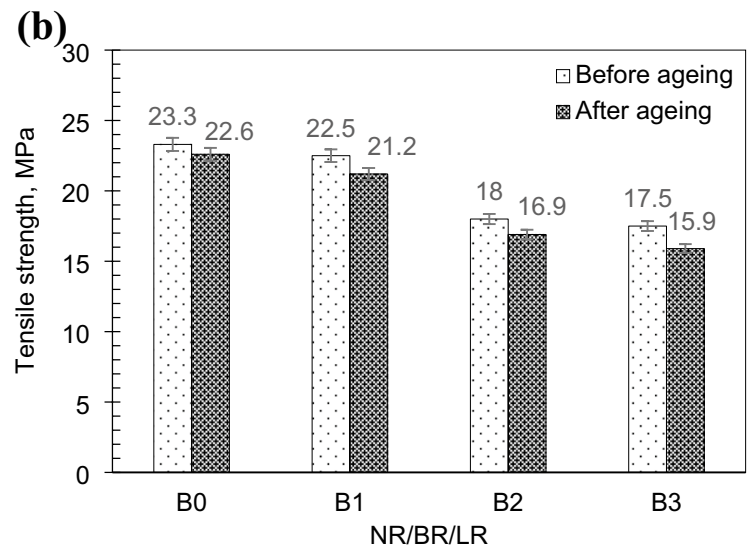

(c)

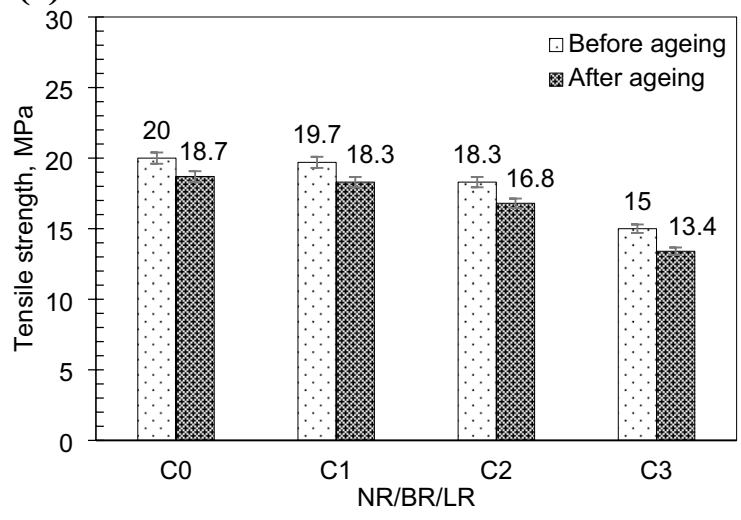

Fig. 2 Plots of tensile strength of A 60/40 NR:BR, B 50/50 NR:BR and C 40/60 NR:BR with various combination LR 


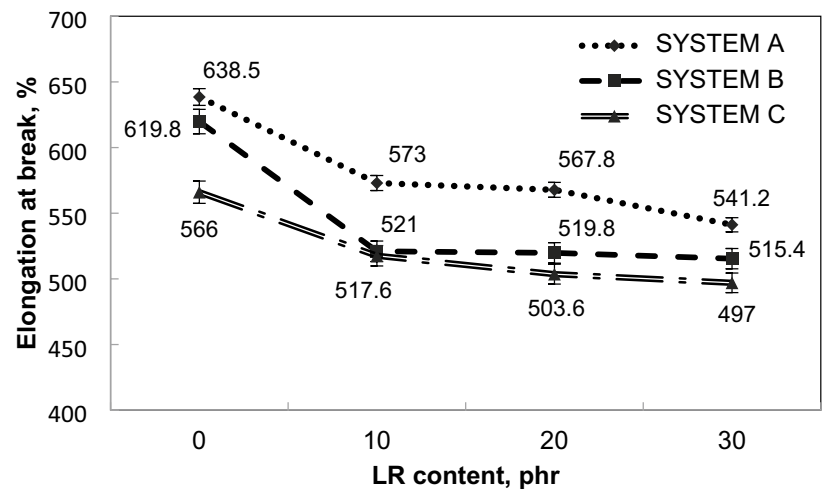

Fig. 3 Plots of elongation at break with various combination of NR/ $\mathrm{BR} / \mathrm{LR}$

content and the molecular weight of rubber hydrocarbon in LR is high compared to black reclaim obtained from used dry rubber products. As the BR content increases, the tear strength starts to decline and is due to the mismatch in crosslink between NR and BR. Also, the cracks can easily propagate through a weak interface resulting in lower tear strength [24].

\section{Abrasion resistance}

The abrasion resistance is usually expressed in terms of volume loss $\left(\mathrm{mm}^{3}\right)$ and as index (ARI). The abrasion resistance of blends having different reclaim content is given in the Fig. 7. The ARI of the samples decreased with the addition of LR. An abrasion rate index of 160 is acceptable for precured tread rubber (PCTR) according to national specification. It is seen that the parameter is well satisfied in systems with higher amount of synthetic rubber (System C) even after the addition of $30 \mathrm{phr}$ of latex reclaim $[25,26]$ whereas $\mathrm{NR}$ rich system (System A) had failed to reach the required limit. In the case of 50/50 blend system (System B), up to $15 \mathrm{phr}$ of latex reclaim was found to be the optimum to get acceptable abrasion resistance.

(a)

(b)

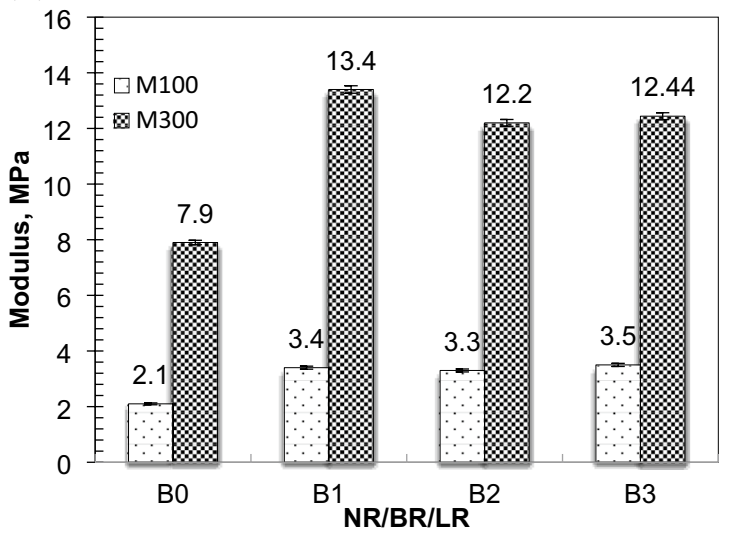

(c)

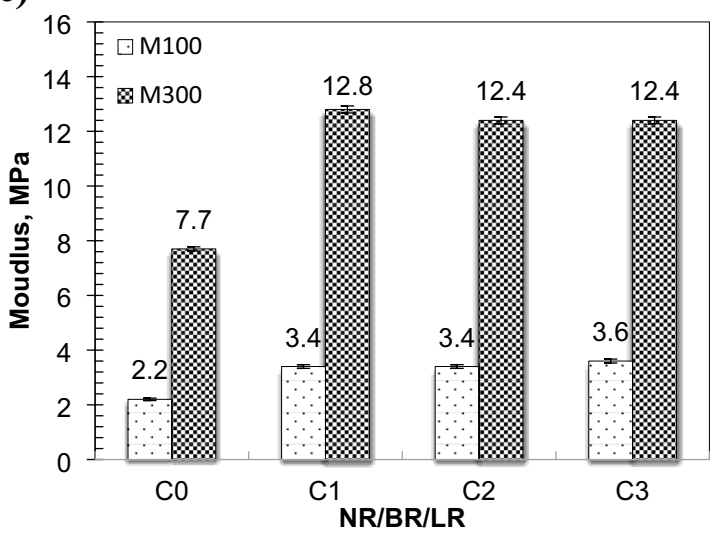

Fig. 4 Plots of modulus of A 60/40 NR:BR, B 50/50 NR:BR and C 40/60 NR:BR with various combination LR 


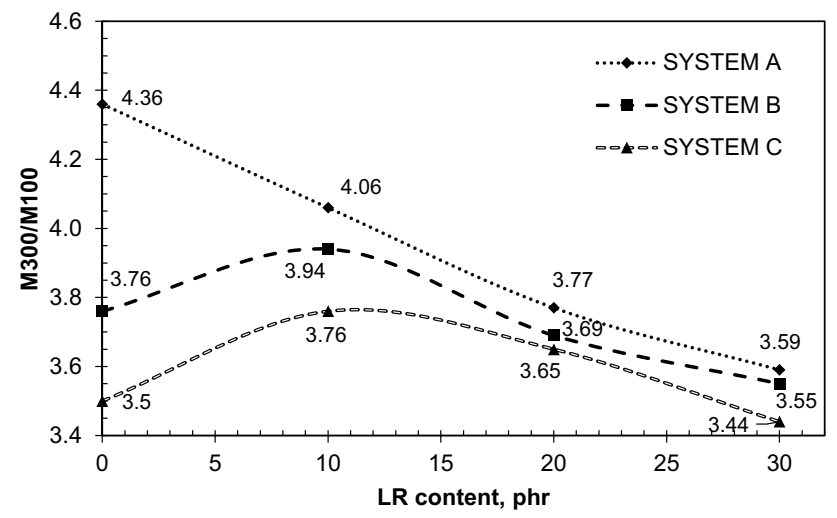

Fig. 5 Plots of M300/M100 with various combination of NR/BR/LR

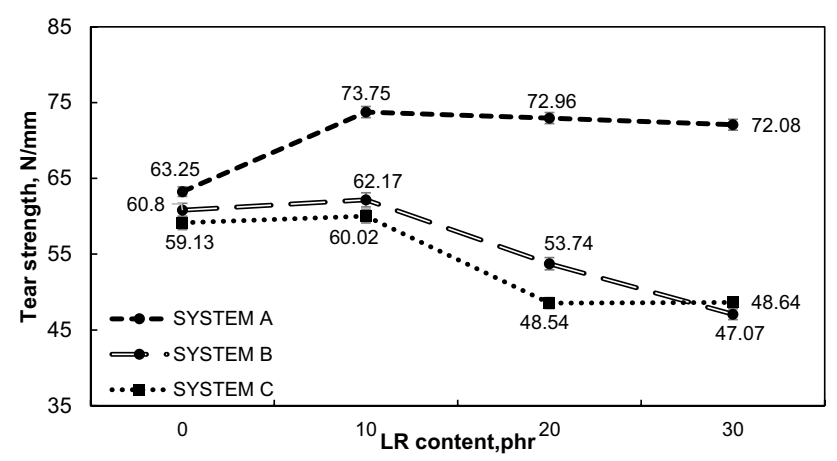

Fig. 6 Plots of tear strength with various combination of NR/BR/LR

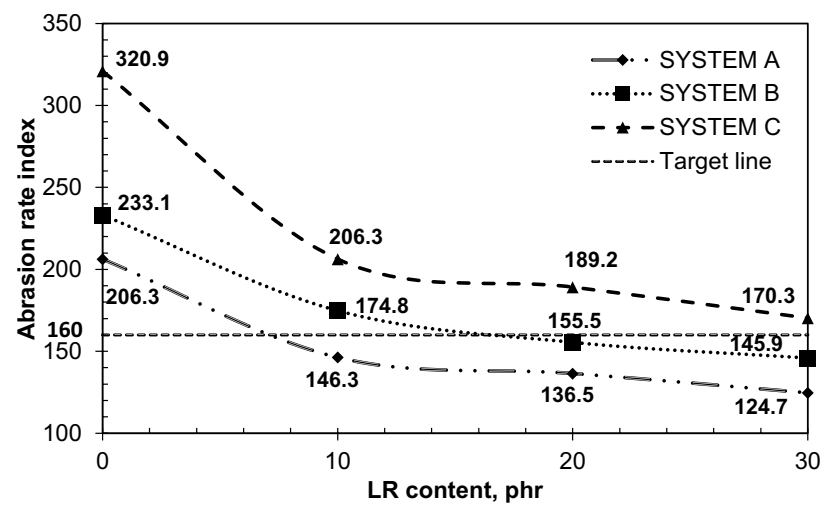

Fig. 7 Plots of abrasion resistance with various combination of NR/ BR/LR

\section{Hardness}

The hardness is found to increase significantly with an increase in the amount of latex reclaim as expected (Fig. 8). This may be due to the enhanced crosslinking in the blends due to the presence of residual curatives from LR. The increased amount of gel and the residual fillers (13\%)

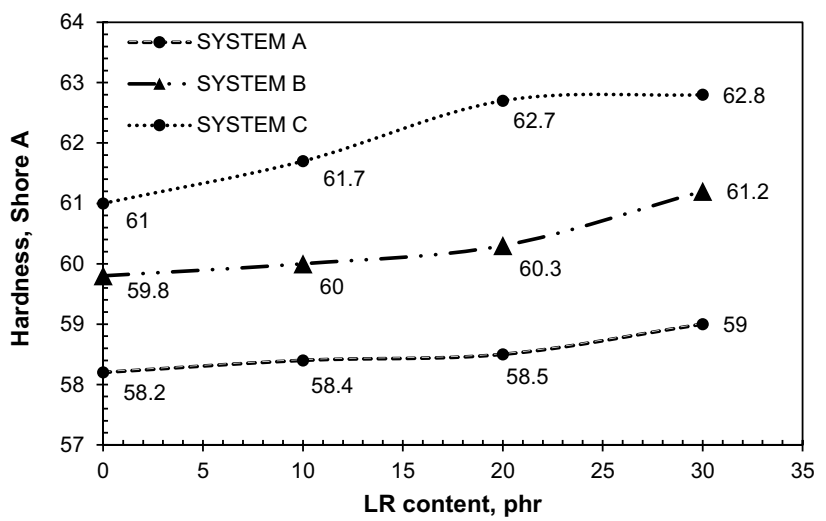

Fig. 8 Plots of hardness with various combination of NR/BR/LR

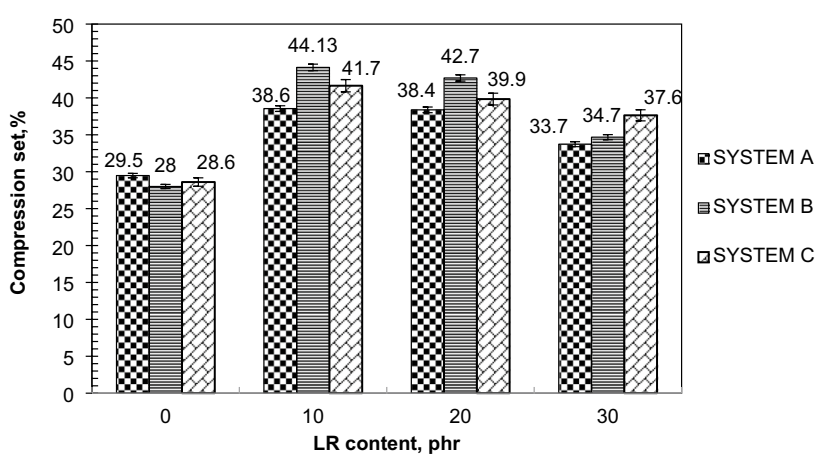

Fig. 9 Plots of compression set with various combinations of NR/BR/ LR

present in reclaimed rubber also contribute to hardness increase [27].

\section{Compression set}

The compression set is found to increase with the addition of latex reclaim. The additional amount of filler and the low molecular weight hydrocarbon are the main reasons for high compression set (Fig. 9). Low elastic material will facilitate irreversible flow under stress resulting in high set values [28]. It was found that the virgin blends ( $\mathrm{A} 0, \mathrm{~B} 0$ and $\mathrm{C} 0$ ) have lower compression set value and are highly elastic. But the compression set value is declining after $10 \mathrm{phr}$ of LR. This can be explained in a different way. The enhanced crosslink density might have improved the elastic nature of the compounds.

\section{Heat build-up}

The elasticity of the material is decreased due to the presence of the high amount of gel in the reclaimed rubber. The reduction in the elastic behaviour may results in increased 
Table 5 Heat-build-up values of various combinations of NR/ $\mathrm{BR} / \mathrm{LR}$

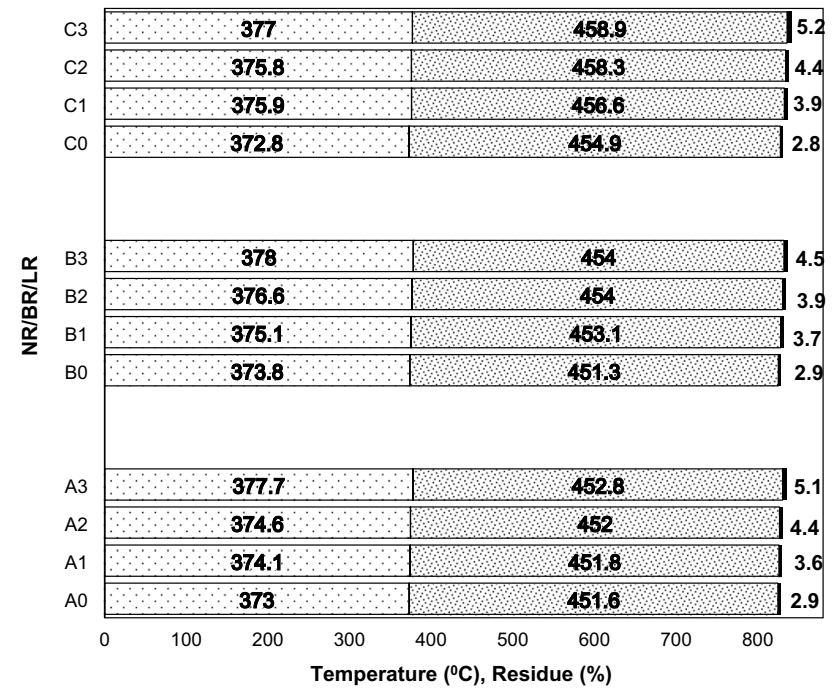

口NR decomposition temperature $\quad \mathrm{B} B \mathrm{R}$ decomposition temperature - Residue

Fig. 10 Thermogravimetric analysis of various combinations of NR/ $\mathrm{BR} / \mathrm{LR}$

heat-build-up values (Table 5). These agglomerate structures may adversely affect the mechanical efficiency of the blends and increase the heat build-up values.

\section{Thermogravimetric analysis}

From thermogravimetric analysis, maximum degradation temperature and percentage residue are represented in Fig. 10. It can be seen that the thermal stability had increased upon addition of LR. This is due to the increased crosslink density as evident from the swelling studies. It can be seen that the blend systems have exhibited two distinct peaks around 373 and $450^{\circ} \mathrm{C}$. These peaks correspond towards the decomposition temperature of NR phase and BR

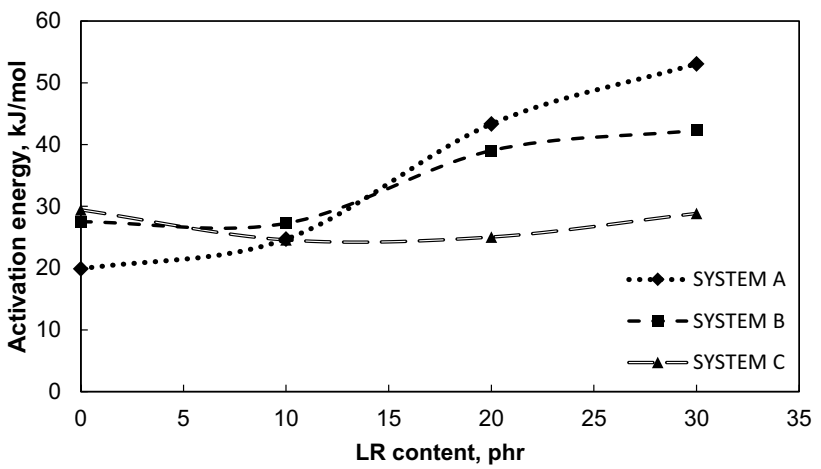

Fig. 11 Plots of activation energy with various combination of NR/ $\mathrm{BR} / \mathrm{LR}$

Table 6 Carbon black dispergrader analysis

\begin{tabular}{lllll}
\hline & X value & White area (\%) & $\begin{array}{c}\text { Average agglom- } \\
\text { erate size } \\
\text { (microns) }\end{array}$ & Dispersion (\%) \\
\hline A0 & 7 & 1.4 & 8.6 & 98.8 \\
A1 & 7 & 1.8 & 9.6 & 98.8 \\
A2 & 6.2 & 3.01 & 10.06 & 97.6 \\
A3 & 6.8 & 2.02 & 9.8 & 98.3 \\
B0 & 7.90 & 0.7 & 7.7 & 99.4 \\
B1 & 6.9 & 1.9 & 9.4 & 98.5 \\
B2 & 5.4 & 2.9 & 10.9 & 96.4 \\
B3 & 5.5 & 3.5 & 10.9 & 96.2 \\
C0 & 8.2 & 0.4 & 8.8 & 99.5 \\
C1 & 6.1 & 3 & 10.3 & 97.5 \\
C2 & 5.9 & 3 & 10.2 & 97 \\
C3 & 5.9 & 3 & 10.1 & 99.5 \\
\hline
\end{tabular}

phase which in turn reflects the thermal stability of the material. It is evident that the thermal stability has been enhanced as the degradation temperature in both of the phases were shifted towards higher temperature. This may be due to the increased crosslink density with the reclaim loading. The increased amount of residue may be originated from the inorganic filler (i.e. $\mathrm{CaCO}_{3}$ ) in the reclaim rubber [29].

According to the activation energy calculated using Coat-Redfern equation (Fig. 11), it has been found that high energy of activation is required to cleave the linkages at high reclaim loading. Upon addition of the reclaim, the amount of filler and the crosslink increased which in turn increased the thermal stability.

\section{Carbon black dispergrader}

The carbon black dispersion is measured in a Dispergrader as per ASTM D2663-08 method B. The X value rating of 1 represents poor dispersion, while a rating of 10 represents 
excellent dispersion; the $\mathrm{Y}$ value rating of 1 represents the practical maximum number of large agglomerates, while a rating of 10 represents the total absence of agglomerates above $23 \mu \mathrm{m}$, that is very good dispersion [30]. From the values (Table 6), it was found that homogenous distribution of carbon black in the blend was slightly affected by the addition of LR. Lower white area values indicate better dispersion. It was noted that the incorporation of LR has negligible effect on percentage of white area. The lower dispersion upon addition of LR may be due to the low viscosity of the resulting rubber compound. Moreover, BR has more affinity for carbon black and as the proportion of BR in the blend increases dispersion rate increases.

\section{SEM analysis}

From the SEM images (Fig. 12), it has been noted that the virgin NR/BR blend has a homogenous morphology whereas with the incorporation of the LR, the morphology is different. Addition of LR (low molecular weight) widen the viscosity between the components of the blends and LR prevents the entanglement and interaction between the NR/BR matrixes resulting in poor adhesion. Insufficient adhesion will result in the formation of cracks and holes which is evident from the images. The increased number of crack paths and holes makes the virgin matrix susceptible to mechanical failure. This can be corroborated from the inferior mechanical properties discussed earlier.

\section{Conclusions}

A series of NR/BR blends were prepared with different loading of LR and their properties were evaluated. It was observed that the cure properties are very much dependent on the amount of LR present in the blend. The residual curatives present in the reclaimed rubber have reduced the cure time and scorch time of the NR/BR blend systems. Tensile strength, abrasion resistance and elongation at break were reduced with the incorporation of LR. Tear strength increased upon addition of $10 \mathrm{phr}$ of LR which decreased on further addition. Moduli at 100 and 300\% elongation were increased due to the increased crosslink density by the addition of LR. Hardness, compression set and heat build-up were found to increase with the increase in the LR content. TGA analysis had showed that the thermal stability has

\section{SEM-ANALYSIS}
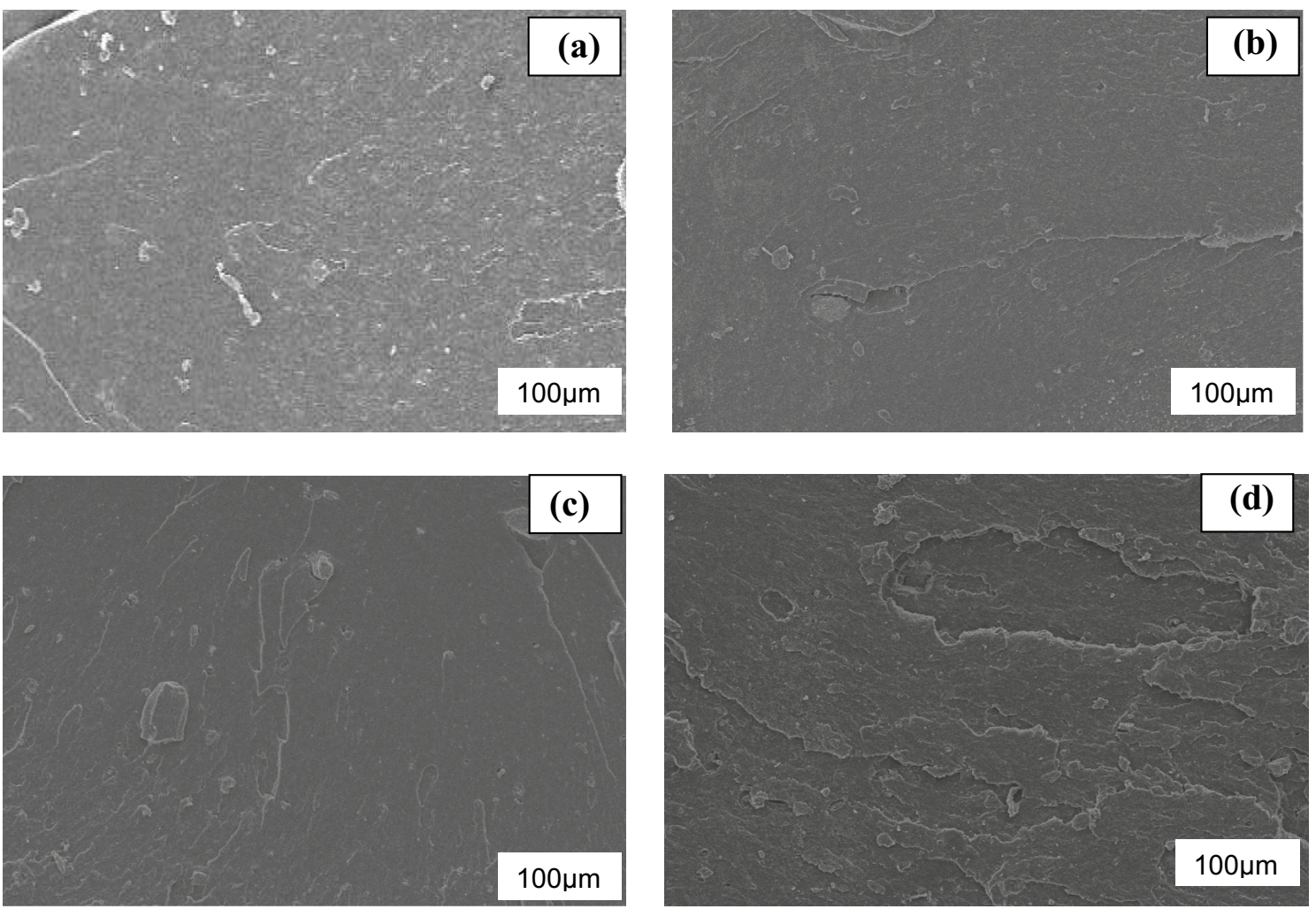

Fig. 12 SEM-analysis. Tensile fractured surface of a NR/BR/LR (50/50/0), b NR/BR/LR (40/50/10), c NR/BR/LR (30/50/20), and d NR/BR/LR (20/50/30) 
increased when the amount of LR is high. The activation energy required for thermal degradation was also found to increase upon addition of reclaimed rubber. The Carbon black dispersion analysis had shown that, a significant reduction in dispersion upon addition of high amount of LR (>10 phr). SEM studies indicated the morphology change due to the viscosity mismatch between NR and BR especially in the presence of LR. From this study the ideal blend proportion having technological specifications conforming to national specification can be selected for developing lowcost tread material.

Acknowledgements The authors are grateful to Rubber Research Institute of India, Kottayam and Cochin University of Science and technology for the technical supports of this work.

Funding The author(s) received no financial support for the research, authorship, and/or publication of this article.

\section{Declarations}

Conflict of interest The author(s) declared no potential conflicts of interest with respect to the research, authorship, and/or publication of this article.

\section{References}

1. Mathew G, Singh RP, Nair NR, Thomas S (2001) Recycling of natural rubber latex waste and its interaction in epoxidised natural rubber. Polymer 42:2137-2165

2. Rajalekshmi S, Joseph R (2002) Studies on the rheology and the mechanical properties of thermoplastic elastomer from latex product waste and high-density polyethylene. J Elastomers Plast 34:313-322

3. Sharib S, Halog A (2017) Enhancing value chains by applying industrial symbiosis concept to the Rubber City in Kedah, Malaysia. J Clean Prod 141:1095

4. Saiwari S, Lohyi E, Nakason C (2013) Application of NR gloves reclaim: cure and mechanical properties of NR/reclaim rubber blends. Adv Mater Res 844:437-440

5. Rajan VV, Dierkes WK, Joseph R, Noordermeer JWM (2006) Science and technology of rubber reclamation with special attention to NR based waste latex products. Prog Polym Sci 31:811-834

6. Rajalekshmi S, Joseph R (2005) Studies on thermoplastic elastomer based on linear low-density polyethylene and latex product waste modified with thiocarbanilide. Int J Polym Mater 54:917-931

7. Thomas KT, Claramma NM, Kuriakose B, Thomas EV (1986) Recycling of natural rubber latex waste. In: Paper presented at the International conference on rubber and rubber-like materials, Jamshedpur, India

8. Burford RP, Pittolo M (1982) Characterization and performance of powdered rubber. Rubber Chem Technol 55:1233

9. Mustafaeva RE (2016) The production and investigation of a rubber mix based on isoprene rubber and modified styrene butadiene rubber. Sov Rubber Technol 43:25-28 (In English)

10. Husna ZNI, Azura AR (2020) Utilization of natural rubber latex as raw materials for rubber shoe outsole. In: 3rd International Postgraduate Conference on Materials, Minerals \& Polymer (MAMIP) doi:https://doi.org/10.1063/5.0016152
11. Jana GK, Das CK (2005) Devulcanization of natural rubber vulcanizates by mechanochemical process. Polym-Plast Technol Eng 44:1399-1412

12. Coats W, Redfern JP (1964) Kinetic parameters from thermogravimetric data. Nature 201:68-69

13. Perera KIDP, Edirisinghe D, Karunanayake L (2020) Characterization of blends of virgin nitrile rubber and compounded nitrile rubber latex waste reclaimed with urea. Part 1: cure characteristics. Prog Rubber Plast Recycl Technol 37:115-130

14. Zhao X, Hu H, Zhang D et al (2019) Curing behaviors, mechanical properties, dynamic mechanical analysis and morphologies of natural rubber vulcanizates containing reclaimed rubber. e-Polym 19(1):482-488

15. Ramarad S, Khalid M, Ratnam CT, Luqman Chuah A, Rashmi WA (2015) Waste tire rubber in polymer blends: a review on the evolution, properties and future. Prog Mater Sci 72:100-140

16. Ismail H, Nordin R, Noor AM (2002) Cure characteristics, tensile properties and swelling behaviour of recycled rubber power-filled natural rubber compounds. Polym Test 21:565-569

17. Awang M, Ismail H, Hazizan MA (2008) Processing and properties of polypropylene-latex modified waste tyre dust blends (PP/ WTDML). Polym Test 27:93-99

18. Salleh SZ, Ahmad MZ, Ismail H (2016) Properties of natural rubber/recycled chloroprene rubber blend: effects of blend ratio and matrix. Procedia Chem 19:346-350

19. Rajan VV, Dierkes WK, Joseph R, Noordermeer JWM (2006) Science and technology of rubber reclamation with special attention to NR-based waste latex products. Prog Polym Sci 31:811-834

20. Rajan VV, Dierkes WK, Joseph R, Noordermeer JWM (2006) Recycling of NR based cured latex material reclaimed with 2,2-dibenzamidodiphenyldisulphide in a truck tire tread compound. J Appl Polym Sci 102:4194-4206

21. Klinggensmith W, Klamp W, Fath M, Baranwal K, Ohm R, Fell RS, Roger B (1997) Rubber compounding, encyclopedia of chemical technology, Forth. Wiley, New York

22. Yun J, Isayev AI (2003) Superior mechanical properties of ultrasonically recycled EPDM rubber. Rubber Chem Technol $76: 253-270$

23. Mittal K (2004) Silanes and other coupling agents. CRC Press, Orlando, Florida

24. Nambiathodi V, Varghese S (2019) Natural rubber/butadiene rubber blend system for tread application. Rubber Sci 32:208-218

25. De D, Prabir KP, Madhusudan R, Satyaban B (2013) Reinforcing effect of reclaim rubber on natural rubber/poly butadiene rubber blends. Mater Des 46:142-150

26. Ajam AM, Al-nesrawy SH, Al-Maamori M (2016) Effect of reclaim rubber loading on the mechanical properties of SBR composites. Int J Chem Sci 14:2439-2449

27. Ghorai S, Mondal D, Hait S, Ghosh AK, Wiessner S, Das A, De D (2019) Devulcanization of waste rubber and generation of active sites for silica reinforcement. ACS Omega 18:17623-17633

28. Deng N, Wang WW, Chen G-W, Zhang Y, Zhang YF, Ma HT (2013) Pyrolysis characteristics of rubber compositions in medical waste. J Centr South Uni 20:2466

29. Hejna A, Zedler L, Przybysz-Romatowska M, Canavate J, Colom X, Formela K (2020) Reclaimed rubber/poly( $\varepsilon$-caprolactone) blends: structure, mechanical, and thermal properties. Polymers 12(5): 1204

30. Otto S, Randl O, Goncalves O, Cantaloube B (2005) New reference value for the description of filler dispersion with the dispergrader 1000 NT. Kautsch Gummi Kunstst 58:390-393

Publisher's Note Springer Nature remains neutral with regard to jurisdictional claims in published maps and institutional affiliations. 